\title{
A internet na escola fundamental: sondagem de modos de uso por professores
}

Gilberto Lacerda Santos

Universidade de Brasilia

\section{Resumo}

Esta investigação objetiva o esclarecimento de modalidades de uso da internet em situações de ensino fundamental, em escolas das redes pública e particular do Distrito Federal. Trata-se de uma pesquisa que empregou leitura qualitativa de dados quantitativos em que, por meio de questionários, entrevistas e observações diretas, abordamos a atuação de vinte professores para explicitar de que forma os conteúdos disponibilizados por meio da internet estão sendo apreendidos e trabalhados em sala de aula, o tipo de navegação nos hipertextos eletrônicos que tem sido proposto aos alunos e uma tipologia de modalidades de uso da internet na educação.

Os dados indicam que há quatro modalidades de navegação (aleatória e linear; orientada e problematizada; por meio de pedagogia de projetos e por meio de abordagens de construção de hipertextos). Indicam também que os professores são capazes de avançar em uma utilização mais interessante da internet como meio de ensino e de aprendizagem e que a escola, com seu ritmo e ritos, constitui uma amarra importante. Sem dúvida, há um clamor geral pela mudança. Se os alunos sentem-se pouco à vontade com a forma e o hermetismo com que as relações educativas vêm sendo conduzidas, o que é traduzido na prática por um desinteresse sistemático pela escola, o mesmo parece acontecer com os professores, sobretudo quando eles são cobrados por gestores, pais, alunos e teóricos da educação para assumirem posturas docentes para as quais eles não foram preparados.

\section{Palavras-chave}

Internet na educação — M odalidades de uso — Trabalho docente.

\footnotetext{
Correspondência:

Gilberto Lacerda Santos

UnB - Faculdade de Educação

Campus Universitário Darcy Ribeiro,

FE3 - Sala AT 26

70910-900 - Brasília - DF

e-mail: glacerda@unb.br
} 


\section{The internet in basic educ ation: a survey of its modes of use by teachers}

Gilberto Lacerda Santos

Universidade de Brasilia

\begin{abstract}
The purpose of this investigation is to clarify the modes of use of the Internet in basic education settings at state and private schools of the Federal District. The research made a qualitative reading of the quantitative data obtained from questionnaires, interviews and direct observations. Twenty teachers were studied to reveal the way in which the contents made available through the Internet are being apprehended and used in the classroom, the kind of navigation of hypertexts that are being suggested to students, and a typology of the modalities of use of the Internet in education.

Data indicate that there are four modes of navigation: random and linear; oriented and problematized; via the pedagogy of projects; through the hypertext creation approach. Data also point out that teachers are able to move forward to a more interesting use of the Internet as a means of teaching and learning, and that the school — with its rhythm and rites constitutes a significant hindrance. Surely, there is widespread call for change. If students feel unease about the form and hermetic way in which educational practices have been conducted, which in actuality reveals itself as a systematic lack of interest in school, the same seems to happen to teachers, above all when they are asked by managers, parents, students and education theorists to adopt teaching attitudes they have not been prepared for.
\end{abstract}

\section{Keywords}

Internet in education — Modalities of use - Teaching.
Contact:

Gilberto Lacerda Santos

UnB - Faculdade de Educação

Campus Univers. Darcy Ribeiro,

FE3 - Sala AT 26

70910-900 - Brasília - DF

e-mail: glacerda@unb.br 
A internet é caracterizada por um entrelaçamento complexo de informações textuais e audiovisuais, umas podendo conduzir a outras, de sorte que sentidos são continuamente construídos pelo leitor, que os gera permanentemente por meio do percurso, em uma espécie de labirinto, em que conjuntos de palavras, imagens e sons se entrelaçam, muitas vezes sem ponto de partida, sem ponto de chegada. É uma rede mundial, que interliga o mundo inteiro, que cristaliza a idéia de aldeia global, conceito proposto por Marshall MacLuhan, formulado no livro The Medium is the Massage, trocadilho com Mass Age, a idade da cultura de massa, a era das comunicações (Macluhan, 1967).

Por tais características, a internet, percebida enquanto suporte para informações hipertextuais com possibilidades infinitas de interseção, demanda uma linguagem própria para sua compreensão, abordagens de leitura não-lineares e, conseqüentemente, apresenta uma textualidade específica para sua apreensão. Inserida no ambiente escolar, a internet é proposta como base para uma nova linguagem para a aquisição e construção de conhecimentos e como uma nova e revolucionária ferramenta para o trabalho docente, na medida em que vivemos em uma sociedade em rede, numa ampla teia de relações sociais na qual cresce, cada vez mais, a exigência de diálogo, interatividade, intervenção, participação e colaboração (Oliveira, 2003).

De fato, no Distrito Federal, assim como em outros contextos, a internet é cada vez mais empregada como meio didático, em todos os níveis de ensino. Muito freqüentemente, professores e alunos, sobretudo de escolas particulares, estão às voltas com a navegação na rede, coletando informações, elaborando trabalhos e, em certos casos, alimentando a net com mais informações, por meio da construção de novos hipertextos, de novos sites. Mas, como os professores estão, efetivamente, inserindo a internet em sua prática profissional? Quais as modalidades de uso, em ambientes escolares, desse meio de comunicação e informação, desse mass media? Será que o trocadilho de MacLuhan tem mais sentido do que pensamos e o uso de tal tecnologia está mais próximo de uma "massagem" no ego de muitos atores da relação educativa do que de uma porta de acesso à era das comunicações, do conhecimento mais acessível, das comunidades em rede, da aprendizagem colaborativa, da edificação de uma relação educativa diferenciada?

Imbuídos desse questionamento mais geral, avançamos, no âmbito do Grupo de Pesquisas Ábaco, da Faculdade de Educação da Universidade de Brasília, em uma sondagem, em escolas públicas e particulares do Distrito Federal, acerca dos modos de uso da internet como meio didático no ensino fundamental, procurando conhecer essa faceta do trabalho pedagógico de vinte professores, sendo dez da rede pública e dez da rede particular. Neste documento, que apresenta os resultados da pesquisa, procuramos recriar os caminhos percorridos, de modo que o leitor possa acompanhar nossa estratégia de construção dos conhecimentos visados, desde a formatação inicial da pesquisa até a elaboração de suas conclusões finais. Primeiramente, apresentamos uma visão geral do contexto em que a pesquisa foi desenvolvida.

Depois, com a finalidade de nos fundamentarmos para a aproximação do campo, apresentamos a base teórica instrumental construída em torno do conceito de hipertexto, a partir dos trabalhos de Snyder (2002), Lévy (1993) e Bakhtin (1981). Em seguida, apresentamos a abordagem metodológica adotada para a coleta de dados e os resultados obtidos. Na última parte, voltamos a uma elaboração teórica, dessa vez focada na construção de algumas considerações sobre a formação de professores do ensino fundamental para o manuseio das novas linguagens de comunicação e informação propostas pela internet. Esta investigação foi conduzida sem nenhuma subvenção e deverá, logo em seguida, ser complementada com outra pesquisa, voltada para os modos de uso da internet pelos alunos. 


\section{Informática na educ ação no Dis trito Federal: informações contextua is}

A situação geral da informática educativa na rede de ensino do Distrito Federal não difere daquela encontrada em outros centros urbanos brasileiros. Por um lado, a informatização das escolas particulares avança rapidamente, muitas vezes sem critério e com situações claras e inequívocas de deslumbramento tecnológico e de sedução de clientes, em detrimento do uso da informática de modo criativo e embasado por intenções educativas. Por outro lado, a informatização das escolas públicas depende de políticas governamentais nem sempre efetivas, da ação de organizações não-governamentais e, em alguns casos, de iniciativas de pais e mestres preocupados com o distanciamento entre essas duas realidades. Moraes (2000 e 2002) apresenta uma história das iniciativas públicas de informática educativa e a realidade do Distrito Federal acaba sendo um subconjunto do retrato apresentado pela autora.

No âmbito do sistema público de ensino, embora a Secretaria de Educação do Distrito Federal jamais tenha tido um programa consistente ou uma política sólida de informática educativa, muitas escolas da rede beneficiamse ou beneficiaram-se de ações do governo federal, que ora promoviam a instalação de laboratórios de informática aqui e acolá, ora faziam com que uma ou outra escola recebesse computadores para uso em ensino e em aprendizagem. A iniciativa atual do Ministério da Educação neste sentido, o Programa Nacional de Informática na Educação (Prolnfo), viabilizou a organização de um Núcleo de Tecnologia Educativa (NTE) na Secretaria de Educação e, em 1999, a formação de uma turma de especialistas em informática na educação, curso elaborado e conduzido pela Faculdade de Educação da Universidade de Brasília. Mas, por razões políticas e de gestão equivocada, os professores formados não foram aproveitados no NTE e dispersaram-se na rede, muitos voltando para a sala de aula, em esco- las desprovidas de equipamentos, onde os especialistas não poderiam sequer aplicar os conhecimentos adquiridos e construídos. De qualquer forma, a equipe que hoje compõe o NTE do Distrito Federal tem envidado esforços em treinamento de professores da rede e na disseminação da cultura da informática na educação.

$M$ ais recentemente, por iniciativa do Instituto Ayrton Senna, de São Paulo, algumas escolas públicas de Brasília receberam laboratórios de informática conectados à internet, obtidos por meio de um concurso de projetos pedagógicos calcados no protagonismo juvenil e na utilização da tecnologia para promoção do potencial humano. Tal iniciativa, por ter sido amplamente divulgada e por ter alcançado, e alcançar ainda, resultados significativos, colaborou bastante para que percepções positivas do uso do computador na educação fossem elaboradas pelos professores.

A Universidade de Brasília, principal fórum de formação de professores no Distrito Federal, não contempla uma formação voltada para a informática educativa em seu programa de Licenciatura em Pedagogia. De modo geral, seu próprio corpo docente não fornece, por meio de sua atuação, exemplos consistentes de utilização do computador na educação. A desativação da formação em tecnologia educativa, nos anos 1980, é precariamente contemporizada com a oferta de disciplinas não-obrigatórias voltadas para o uso do vídeo e da informática na escola.

Mais recentemente, com a extraordinária emergência de instituições particulares de ensino superior no Distrito Federal, muitos cursos de pedagogia, geralmente noturnos, foram implementados. Alguns poucos contemplam uma formação em informática educativa, o que demanda, pelo menos, um laboratório de informática na instituição, transformando este curso "baratinho", oferecido por qualquer faculdade de "fundo de quintal", em uma opção mais onerosa. Então, a maioria ignora a existência dos computadores e seu potencial como meio didático. 
Já na rede particular, a situação é melhor em termos de quantidade, mas não necessariamente em termos de qualidade. A quase totalidade das escolas particulares de ensino fundamental dispõe de laboratórios de informática que são alardeados aos pais e clientes como indicadores de qualidade de ensino e de modernidade das instituições. Mas o corpo docente, oriundo dos mesmos fóruns que o da rede pública, não tem a formação necessária para o uso criativo e contextualizado da informática na sala de aula. Em algumas dessas escolas, onde a vontade de inovar pelo menos existe, os laboratórios de informática são conduzidos por técnicos de informática, sem nenhuma formação pedagógica, e surge todo o problema da descaracterização do trabalho docente, discutido por Almeida (2001), na medida em que o professor regente não acompanha seus alunos no uso do computador como apoio à aprendizagem. 0 Departamento de Ciência da Computação da UnB tem envidado esforços no sentido de amenizar essa situação e instituiu um curso de Licenciatura em Informática, no qual os profissionais de computação obtêm uma formação em educação, situando-se na interface entre a informática e a pedagogia. Não é a medida ideal, pois cabe ao profissional de educação deter os conhecimentos e as habilidades necessárias para manusear os meios didáticos de que necessita para sua atuação na relação educativa. Mas já seria um grande avanço poder contar com "informatas- pedagogos".

Tal cenário vem sendo também confirmado em uma pesquisa de iniciação científica conduzida por Braga e Lacerda Santos (2002), voltada para o mapeamento de modalidades de uso do computador na educação infantil. Nesse contexto, a comparação entre as redes pública e particular é igualmente dicotômica, revelando que ainda há muito caminho a se percorrer para que não apenas o computador, mas as novas tecnologias de comunicação e informação possam vir a tornarem-se meios didáticos no sentido próprio do termo.

Além do cenário desenhado, os professores do Distrito Federal, de modo geral e como os de outros contextos, têm sido alvo da mídia impressa e televisiva no que diz respeito ao potencial do computador na educação. Assim, toda uma gama de representações sociais e de expectativas positivas com relação a tal tecnologia de comunicação e informação vem sendo edificada ao longo do tempo. Conseqüentemente, seja do ponto de vista empírico, seja do ponto de vista teórico, os professores estão cada vez mais habituados com a cultura da informática educativa e, via de regra, têm grande curiosidade com relação ao tão alardeado potencial pedagógico da informática de modo geral e da internet em particular, ainda por serem elucidados.

\section{Internet, hipertextualidade e interatividade}

Considerando o contexto explicitado, voltemos ao eixo condutor da pesquisa aqui relatada, que se refere às modalidades de uso da internet por professores do sistema de ensino fundamental do Distrito Federal. Como já foi salientado, antes de abordarmos o campo, sentimos necessidade de formatação de uma base teórica instrumental em torno de alguns conceitos próprios à internet, como 0 de hipertexto, interatividade, navegação, comunidades virtuais, etc.

Snyder (2002) descreve a internet como um labirinto, espaço de interações, de caminhos certos e incertos em meio ao conhecimento disperso no espaço virtual. Para a escola, a autora anuncia grandes possibilidades, desde que os atores das relações educativas estejam conscientes da natureza deste "terreno virtual". Enquanto hipertexto eletrônico, a internet não apenas inova o texto e seu modo de apresentação e leitura, como também propõe novos gêneros de textos e novas modalidades de leitura. Diferentemente do hipertexto impresso, o eletrônico revoluciona a relação entre 0 autor e o leitor, fazendo com que um e outro mudem de lugar constantemente, ocasionando o que Lévy (1993) chama de desterritorialização. No 
entanto, tudo depende do modo como o relacionamento com a internet é estabelecido. De fato, é muito comum presenciarmos, em ambientes escolares, situações de tratamento totalmente tradicional a hipertextos cuja dinâmica impõe uma leitura não-linear, com outro ritmo, com outra cadência. As observações de Snyder (2002) nos conduziram à necessidade de compreendermos melhor o tipo de leitura, de navegação na internet que os professores vêm propondo a seus alunos, uma vez confrontados a este conjunto de nós ligados por conexões em constante transformação, construção e renegociação (princípio da metamorfose), sob diferentes formatos (princípio da heterogeneidade), escalonadas em diferentes níveis de rede (princípio da multiplicidade), permanentemente aberta a novas inserções (princípio da exterioridade), estabelecendo proximidade entre diferentes significações (princípio da topologia) e sem centro definido (princípio da mobilidade). Tais princípios ou características da rede hipertextual, propostos por Lévy (1993), indicam caminhos para se analisar as estratégias de navegação na internet empregadas pelos professores visados pela investigação. Por essa via, estaremos focando a "forma" da interação.

Mas não estávamos unicamente interessados nas formas de leitura de hipertextos, isto é, de navegação na internet. Importava-nos também compreender a natureza dos processos interativos estabelecidos com o conteúdo da internet, verificar se os professores estabelecem uma interação dialógica com os conteúdos abordados na rede, na perspectiva bakhtiniana do termo, em que diferentes vozes, no caso diferentes autores/leitores de hipertextos interligados, negociam sentidos e constroem conhecimentos coletivamente (Bakhtin, 1981). Nessa perspectiva, o uso da internet como meio didático estaria efetivamente relacionado a abordagem de novas formas de construção de conhecimentos, de novas linguagens de comunicação, informação e cognição. Por essa via, estaremos focando o "conteúdo" da interação.

Assim sendo, o questionamento geral que esteve na gênese da investigação foi traduzido em questões mais específicas, que subsidiaram a construção dos instrumentos de coleta de dados. Tais questões específicas foram as seguintes: De que forma os conteúdos disponibilizados por meio da internet estão sendo apreendidos e trabalhados em sala de aula? Que tipo de navegação na internet os professores propõem a seus alunos? Que tipologia de modalidades de uso da internet na educação pode ser construída a partir da observação da prática dos professores?

\section{Abordagem metodológica e resultados obtidos}

Para o desenvolvimento do trabalho visado, selecionamos vinte escolas sendo dez públicas e dez particulares. De cada conjunto, cinco escolas localizam-se no Plano Piloto e as demais nas cidades satélites de Taguatinga, Sobradinho, Gama, Guará e Brazilândia. Os dados foram coletados por meio de três abordagens distintas e complementares, em uma perspectiva de cruzamento de leituras qualitativas de dados quantitativos: questionários, entrevistas e observação direta de situações educativas nas quais a internet foi empregada como meio didático.

Os professores abordados colaboraram com muita presteza e a investigação foi "concluída" ao fim de cinco meses de trabalho. Evidentemente, o recorte principal de nosso trabaIho, no que diz respeito às características do público-alvo, era o fato de que os professores a serem abordados deveriam utilizar a internet em sua prática pedagógica. A amostragem aleatória delimitada foi constituída por professores que tinham entre 27 e 35 anos de idade e menos de 10 anos de exercício da profissão. Setenta e cinco porcento deles concluíram seus cursos de pedagogia em instituições particulares de ensino superior e todos se manifestaram extremamente abertos e positivos com relação às aplicações pedagógicas das novas tecnologias de comunicação e informação. Todos eram professores com dedicação exclusiva ao exercício da docência, mas apenas 15\% deles procuraram fazer algum tipo de curso de 
formação continuada. Entre os professores das escolas particulares, todos tinham computador em casa, com acesso à internet. Entre os professores das escolas públicas, apenas $40 \%$ vivenciavam tal situação. Dos $60 \%$ restantes, $10 \%$ tinham computador sem acesso à internet. Nenhum deles teve formação em informática educativa em seus respectivos cursos de pedagogia. A aproximação com a tecnologia como meio de ensino foi construída pela leitura de revistas especializadas, pelo contato com experiências de sucesso divulgadas na mídia, pela participação em ações de informática educativa promovidas pela iniciativa governamental, pela iniciativa privada ou por organizações do terceiro setor.

Os vinte questionários encaminhados às vinte escolas selecionadas revelaram que os conteúdos disponibilizados por meio da internet estão sendo apreendidos e trabalhados em sala de aula de modo extremamente aleatório, com pouca ou nenhuma atuação didática consciente por parte da maioria os professores. Estes, por total falta de familiaridade com a linguagem dos hipertextos eletrônicos - e ignorando a natureza deste conceito -, geralmente solicitam a seus alunos pesquisas sobre temas diversos, que são imediatamente traduzidos por "acessar, achar e imprimir". A diferença entre a rede pública e a rede particular está unicamente na freqüência com que a tecnologia é empregada. Enquanto um professor de uma escola particular vai solicitar muitas vezes aos seus alunos que investiguem conteúdos na internet, geralmente uma vez por semana, os professores das escolas públicas 0 fazem, de modo geral, uma vez por semestre. Em qualquer dos casos, a internet é encarada como uma espécie de livro eletrônico, em que não é preciso folhear as páginas nem ir à biblioteca. Basta digitar uma palavra e solicitar a busca. Depois basta escolher um texto, lê-lo e imprimilo. Dos professores consultados, apenas quatro estabelecem uma relação macrocognitiva com os conhecimentos oferecidos por meio da internet, fazendo pesquisas prévias de conteúdos, selecionando sites, estudando seus conteúdos e elaborando questionamentos sobre tais conteúdos, de modo que os alunos terão que ir além da simples busca e impressão e atingir o estágio da leitura contextualizada, da compreensão motivada e da resolução de problemas, em uma dinâmica de pesquisa orientada de conteúdos. Três professores indicaram que os conteúdos da internet são empregados de forma integrada com outros conteúdos, em situações de desenvolvimento de projetos pedagógicos. Nesses casos, os conteúdos dos hipertextos eletrônicos são abordados livremente pelos alunos em função de necessidades de desenvolvimento de suas problemáticas de investigação, em seus projetos pedagógicos.

A esse respeito, importa evidenciar a utilização cada vez maior da pedagogia de projetos como estratégia de gestão de situações educativas em que há utilização do computador, por professores que não têm formação específica ou especializada para tal atuação (Lacerda Santos, 2003). Finalmente, um único professor indicou que propõe a seus alunos uma abordagem de inserção de conteúdos na internet por meio da construção de novos documentos hipertextuais. Esse professor domina linguagens de programação e ferramentas de construção de hipertextos eletrônicos e procura incentivar seus alunos a também dominarem tais ferramentas, consideradas pelo professor como vitais para a escola da sociedade da informação.

Enfim, essa primeira parte da investigação revelou que os conteúdos disponibilizados por meio da internet estão sendo apreendidos e trabalhados em sala de aula de acordo com a seguinte tipologia:

1. por meio de pesquisa aleatória e linear (55\% das respostas, onze casos);

2. por meio de pesquisa orientada e problematizada ( $20 \%$ das respostas, quatro casos);

3. por meio de pedagogia de projetos $(15 \%$ das respostas, três casos);

4. por meio de abordagens de construção de hipertextos (10\% das respostas, dois casos).

Em seguida, tomando como parâmetro os resultados da aplicação dos questionários, 
selecionamos oito professores para serem entrevistados e observados em sua prática pedagógica, com vistas a um aprofundamento do conhecimento acerca do uso da internet em sala de aula. Esses professores foram selecionados por representarem casos típicos da situação observada. Quatro eram de escolas públicas e quatro de escolas particulares. Em cada conjunto, um empregava a internet aleatoriamente e de forma linear, um a empregava de forma orientada, um em situações de pedagogia de projetos e um em situações de construção de hipertextos.

As entrevistas e as observações revelaram que há um distanciamento generalizado entre as teorias que propõem usos inovadores da internet na educação e a prática efetiva dos professores. A construção coletiva de conhecimentos e a negociação de sentidos, possibilidades advindas de leituras dos trabalhos de Bakhtin (1981), são situações que inexistem na prática, tendo em vista que os professores abordados jamais tiveram formação inicial ou continuada nesse sentido. Aliás, a própria coletivização do trabalho discente ainda é uma caixa preta a ser desvendada na prática da sala de aula, seja em que contexto for. As navegações propostas, mesmo em situações mais estimulantes de pedagogia de projetos ou de construção de sites, são extremamente lineares e distanciadas do sentido labiríntico proposto por Snyder (2002). Em sala de aula, sem nenhuma exceção, a internet não é conceituada para os alunos. Sua origem, forma, modo de funcionamento, possibilidades de navegação, estrutura ou função não são tratados pelos professores que, até mesmo como estratégia de reprodução de formas de controle da situação didática, propõem a seus alunos abordagens lineares, previsíveis e estáticas na navegação na rede.

As observações das relações educativas revelaram também o já costumeiro descompasso entre a forma como os professores e os alunos se relacionam com os hipertextos eletrônicos e sua linguagem não-linear. Enquanto os professores lidam com a internet com uma rigidez que não condiz com a flexibilidade e as inúmeras possibilidades de leitura e construção de sentidos dos hipertextos eletrônicos, os alunos, mais familiarizados com abordagens não-lineares advindas de outras situações (jogos eletrônicos, cinema, desenhos animados, etc.), demonstram total capacidade de avançar mais livre e "desordenadamente". No entanto, todo o ímpeto dos alunos é categoricamente controlado pelos professores, que confundem liberdade com desordem, criatividade com desconexão, iniciativa com rebeldia. Nas dez situações educativas observadas, mesmo naquela em que os alunos construíam páginas para a internet, os papéis de alunos e professores eram tradicionais, formais e acomodados na hierarquia secular que separa docentes de discentes; e estes, do conhecimento.

\section{Considerações fina is}

Desenvolver a idéia, a título de conclusão deste artigo, de que os programas de formação de professores precisam integrar componentes curriculares que tratem das novas mídias e de seus modos de uso em educação seria redundante e desnecessário. No entanto, é importante frisar que o uso da internet na sala de aula apresenta desafios importantes para o professor formado pelos mecanismos tradicionais de profissionalização docente, como enfatizam Silva (2000) e Kenski (2003). Primeiramente, há a necessidade de rompimento com a dinâmica da escola da sociedade industrial, na qual os alunos têm de abordar os mesmos conteúdos, ao mesmo tempo, da mesma forma e em busca dos mesmos resultados, a fim de serem submetidos à mesma avaliação. Em seguida, há a necessidade de rompimento com materiais didáticos fechados, estáticos, que permitem o controle da cognição e da construção de conhecimentos, como se isso fosse possível. Também, é importante que o professor volte sua atenção para a criatividade como meio de aprendizagem e para o potencial do aluno em inovar a relação educativa, já que o docente tem amarras ideológicas e contextuais que, geralmente, o impedem de fazê-lo. Do universo de professores 
abordados nessa investigação, $45 \%$ sinalizaram, apesar dos problemas infra-estruturais e das limitações de formação, que são capazes de avançar em uma utilização mais interessante da internet como meio de ensino e de aprendizagem. Mas a escola constitui uma amarra importante; o currículo tradicional, com seu ritmo e seus rituais, é um significativo ponto de estrangulamento; os mecanismos em voga de formação de professores precisam ser urgentemente revistos e atualizados. Sem dúvida, há um clamor geral pela mudança. Se os alunos sentem-se pouco à vontade com a forma e o hermetismo com que as relações educativas vêm sendo conduzidas, o que é traduzido na prática por um desinteresse sistemático pela escola, o mesmo parece acontecer com os professores, sobretudo quando eles são cobrados por gestores, pais, alunos e teóricos da educação para assumirem posturas docentes para as quais eles não foram preparados.
Evidentemente, é possível romper com tal situação e houve evidências disso nas observações e entrevistas realizadas nessa investigação. Em mais de uma ocasião, os professores demonstraram interesse e vontade de inovar mas estavam de mãos vazias, sem instrumentos teóricos e empíricos para isso, de modo que 0 uso da internet ainda é bastante limitado, embrionário e aquém das possibilidades desse poderoso meio de comunicação e informação. No entanto, o professor não é o vilão dessa história. Existe avidez e grande expectativa por formação continuada nesse sentido, 0 que revela que os professores estão prontos para o emprego de novas ferramentas em seu trabalho docente. Cidadãos de dois mundos, todos os professores consultados têm representações individuais extremamente favoráveis com relação ao uso de tecnologias na educação o que sinaliza positivamente para a aproximação entre as linguagens da sociedade da informação e da escola.

\section{Referências bibliográfic as}

ALMEIDA, Maria Elizabeth Biancocini de. Informática e formação de professores. Brasília: Ministério da Educação/Proinfo, 2001. (Informática para a mudança na educação).

BAKHTIN, Mikhail. Problemas da poética de Dostoievski. Rio de J aneiro: Forense, 1981.

BRAGA, Camila Brasil; LACERDA SANTOS, Gilberto. Modalidades de uso do computador em educação infantil. In: CONGRESSO DE INICIAÇÃO CIENTíFICA DA UNIVERSIDADE DE BRASÍLIA, 2002, Brasília. Anais. Brasília: Universidade de Brasília, 2002.

KENSKI, Vani. Tecnologias e ensino presencial e a distância. Campinas: Papirus, 2003.

LACERDA SANTOS, Gilberto. A gestão de relações educativas apoiadas pelo computador por meio da pedagogia de projetos. In: . (Org.), Tecnologias na educação e formação de professores. Brasília: Editora Plano, 2003. p. 49-68.

LÉVY, Pierre. As tecnologias da inteligência. Trad. Carlos Irineu da Costa. Rio de J aneiro: Editora 34, 1993.

MACLUHAN, Marshall; FIORE, Quentim; J EROME, Agel. The medium is the massage. New York: McGraw-Hill, 1967.

MORAES, Raquel de Almeida. Informática na educação. Rio de J aneiro: DPA, 2000. Rumos da informática educativa no Brasil. Brasília: Editora Plano, 2002.

OLIVEIRA, Elsa G. Educação a distância na transição paradigmática. Campinas: Papirus, 2003. 
SILVA, Marco. Sala de aula interativa. Rio de J aneiro: Editora Quartet, 2000.

SNYDER, llana. Hypertext: the electronic labyrint. New York: New York University Press, 2002.

Recebido em 11.06 .03

Aprovado em 02.09 .03

Gilberto Lacerda Santos é professor-adjunto da Faculdade de Educação da Universidade de Brasília. Graduado em Matemática, mestre em Tecnologias na Educação pela Universidade de Laval (Canadá) e Ph.D. em Educação pela mesma universidade é doutor em Sociologia do Conhecimento pela Universidade de Brasília. Atua em ensino, pesquisa, extensão e consultoria na área das aplicações pedagógicas das novas tecnologias de comunicação e informação, particularmente do computador. 